\title{
Frequency of Carcinoma Prostate in Patients presenting with Clinically Benign Enlarged Prostate
}

\author{
Fazli Akbar, Anwar ul Haq, Nizam ud din, Mohammad Hussain, Zia ur Rehman, Amir Amanullah
}

\section{ABSTRACT}

Background: Benign Prostatic hyperplasia is one of the commonest physiological ageing process of males. Among these, there are chances of conversion of this benign condition into malignancy. Initially benign prostatic hyperplasia was tried to be controlled with medication. Then came the era of open surgery in the form of Trans-vesical prostatectomy and now-a-days minimally invasive technique of trans-urethral prostatectomy is on the surge. With the passage of time, there is increasing trend in performing histo-pathology of any tissue taken out from the body and this has resulted in very fruitful results.

Objective: To determine the frequency of carcinoma prostate in those patients who were clinically suspected as having bening enlarged prostate.

Material and Methods: This study was conducted in Surgical units and Urology unit of Saidu Group of Teaching Hospitals, Swat from 2013 to 2015. A total of 200 patients were included in the study. An exclusion criteria was made so as to exclude confirm cases of carcinoma prostate from the study. After performing trans-vesical and trans-urethral prostatectomy, the specimens were sent for histopathology.

Results: 200 patients were selected for the study who were clinically assigned as having benign prostatic hyperplasia according to our inclusion criteria. Out of these 200 subjects, $32(16 \%)$ came out to be having carcinoma prostate while 168 (84\%) patients retained the original clinical diagnosis upon histo-pathology.

Conclusion: Rather than assigning a patient as having benign enlarged prostate on clinical grounds, it is better to perform histopathology because there is a vast difference of management plan of a benign condition as compared to a malignant condition.

Key Words: Prostatitis, Benign prostatic hyperplasia, prostatic carcinoma, Digital rectal examination, International prostate symptoms score, Trans-vesical prostatectomy, Prostate specific antigen, Histo-pathology.

This article may be cited as: Akbar F, Haq, UA, Din UN, Hussain M, Rehman UZ, Amanullah A. Frequency of Carcinoma Prostate in Patients presenting with Clinically Benign Enlarged Prostate. J Saidu Med Coll Swat 2020;10(1):56-60

\section{INTRODUCTION}

Frequent pathologies are associated with prostate such as Prostatitis, Benign prostatic hyperplasia and carcinoma 1 . Benign prostatic hyperplasia does not appear to cause or predict the presence of prostatic cancer ${ }^{2}$. Carcinoma prostate is the second most common leading cause of death after lung cancer in men $^{3}$. Carcinoma prostate should not be suspected in patients with short duration of symptoms i.e. lasting from 15 days to one month ${ }^{4}$. An incidental diagnosis of carcinoma is made in about $15 \%$ of patients undergoing transurethral or open surgery for prostatic adenoma. "True" incidental prostate cancer was defined as cases where the preoperative digital rectal examination (DRE) and the prostatespecific antigen (PSA) values were normal ${ }^{5}$ (Normal PSA level is less than $2.5 \mathrm{ng} / \mathrm{ml}$ ). Incidental prostatic cancer is prostate adenocarcinoma discovered by chance in contrast to stages pT2-4 $4^{6}$. It is not a pathologically defined tumor stage but includes a heterogeneous population of cancers with different extents of invasions and is only characterized by the mode of its clinical presentation ${ }^{7}$. The PSA assay, DRE and TRUS provides tools for detecting prostate cancer at a very early stage, when it is still organ confined

Department of Surgical, Saidu Group of Teaching Hospital, Swat

Correspondence: Dr. Fazli Akbar

Assistant Professor Surgical A Unit SGTH, Swat

Email:dr.fazliakbar2001@gmail.com and thus curable ${ }^{8}$. Digital rectal examination has shown sensitivity of $63 \%$ and specificity of $73.22 \%$. The sensitivity of PSA was $87 \%$ and specificity was $70.8 \%$. PSA presents an important adjunct to DRE for detection of prostate carcinoma ${ }^{9}$. The biological activity of prostate carcinoma appears to be independent of serum PSA. Previous prostate biopsy in patients with suspicious digital rectal examination or elevated PSA diminishes the prevalence of incidental prostate cancer. The diagnosis is confirmed by needle biopsy of suspicious area of prostate or by histological examination of surgically removed prostatic tissues ${ }^{10}$. It is recommended that radical prostatectomy should be done to patients who are candidates for further curative therapy in incidental findings ${ }^{11}$.

Very regular follow up is required for incidentally diagnosed malignancies of prostate. The number of incidentally detected prostatic carcinoma decreased with time.

The prostate gland usually begins to enlarge at the age of 40 years, although microscopic benign prostate enlargement is recognizable at 30 years ${ }^{12}$. Significant symptoms requiring treatment may be noted in up to $10 \%$ of men ${ }^{13}$ although mild or moderate symptoms may go unnoticed as they are often mistaken for normal ageing by many men $^{14}$. The full spectrum of disease can only be seen in the routine postmortem examination of 
prostate glands however, some insight into the disease process can be obtained in clinical practice through the study of symptomatic patients ${ }^{15}$.

\section{Rationale}

This study is designed to detect the frequency of carcinoma prostate in patients presenting with clinically benign enlarged prostate. This will bring a positive change to our current practice and will detect the carcinoma prostate at an early stage. This practice will decrease the mortality and morbidity associated with carcinoma prostate. Furthermore this will be shared with our fellow colleagues at national and international level and will help us in devising standard protocols for investigating benign prostatic hyperplasia.

\section{MATERIALAND METHODS}

Cross sectional study in Surgical units and Urology unit of Saidu Group of Teaching Hospitals, Swat from Jan 2013 to June 2015. This study was done in three years. 200 patients were included in this study. Non-Probable purposive was used as sample technique.

\section{Inclusion Criteria}

1. Clinically benign looking prostate. Features of benign prostate on digital rectal examination are:

Smooth surface with smooth borders.

Absence of nodularity in prostate gland.

Mobile rectal mucosa over prostate.

Palpable median sulcus between both lobes of prostate.

2. Severe International Prostate Symptoms Score.

3. Post void residual urine more than $100 \mathrm{ml}$ on sonogram.

4. S. PSA less than $4 \mathrm{ng} / \mathrm{ml}$.

\section{Exclusion Criteria}

1. Patients with known malignancy of prostate.

2. Patients with mild to moderate International
Prostate Symptom Scores.

3. Suspicion of malignancy on digital rectal examination.

4. S. PSA more than $4 \mathrm{ng} / \mathrm{ml}$.

After taking a well informed consent, patients presenting to surgical OPD and urology OPD with severe IPSS score and fulfilling the inclusion and exclusion criteria were admitted to surgical units and urology unit of Saidu group of teaching hospitals, Swat. By taking demographic details, proper history, performing proper examination, doing relevant investigations which include baseline investigations in the form of full blood count, random blood sugar, urine R/E, ECG, CXR and specific investigations in the form of Renal function tests, abdominal ultrasonography and biopsy, operating (Trans-vesical and Transurethral prostatectomy) followed by histopathological reports, all these details were entered into specially designed Proforma.

All the data were entered into SPSS 16.0 version for analysis. Descriptive statistics like mean $\pm S D$ for age of patients and for histo-pathological report of prostate specimens were calculated accordingly.

\section{RESULTS}

During the 3 years study period, 200 patients with clinically benign enlarged prostate were included in the study. Carcinoma prostate was detected in $32(16 \%)$ patients among these 200 patients histologically. The patients with benign enlarged prostate had the mean age of 66.1 years (range 45---85) and 32 with histologically diagnosed prostate cancer had mean age 68.3 years (range 45---85).

Most of the patients had previous symptoms of prostatism for longer duration as mentioned in table 1.

Table 1. Duration of symptoms.

\begin{tabular}{|l|l|}
\hline Duration of symptoms & No of patients \\
\hline$<1$ month & 35 \\
\hline 2 months to 6 months & 42 \\
\hline 7 months to 1 year & 104 \\
\hline$>1$ year & 19 \\
\hline
\end{tabular}


Table 2. International Prostate Symptoms Score (I-PSS)

\begin{tabular}{|l|l|l|l|l|l|l|}
\hline In the past month & $\begin{array}{l}\text { Not at } \\
\text { all }\end{array}$ & $\begin{array}{l}\text { Less than } \\
1 \text { in } 5 \text { times }\end{array}$ & $\begin{array}{l}\text { Less than } \\
\text { half the } \\
\text { time }\end{array}$ & $\begin{array}{l}\text { About } \\
\text { half the } \\
\text { time }\end{array}$ & $\begin{array}{l}\text { More than } \\
\text { half the time }\end{array}$ & $\begin{array}{l}\text { Almost } \\
\text { always }\end{array}$ \\
\hline Incomplete emptying & 0 & 1 & 2 & 3 & 4 & 5 \\
\hline Frequency & 0 & 1 & 2 & 3 & 4 & 5 \\
\hline Intermittency & 0 & 1 & 2 & 3 & 4 & 5 \\
\hline Urgency & 0 & 1 & 2 & 3 & 4 & 5 \\
\hline Weak stream & 0 & 1 & 2 & 3 & 4 & 5 \\
\hline Straining & 0 & 1 & 2 & 3 & 4 & 5 \\
\hline & None & 1 time & 2 times & 3 times & 4 times & 5 times \\
\hline Nocturia & 0 & 1 & 2 & 3 & 4 & 5 \\
\hline
\end{tabular}

Table 3. Frequency of Benign and malignant prostate

\begin{tabular}{|c|c|}
\hline Tot al number of patients & 200 \\
\hline Benign enlarged prostate with inflammation & $168(84 \%)$ \\
\hline Carcinoma prostate & $32(16 \%)$ \\
\hline
\end{tabular}

Score: $\quad 1---7$ :

Mild $\quad 8---19$ :

Moderate 20---35: Severe

A detailed histological analysis was observed for all the specimens. The mean weight of the enucleated prostates was $38.9(15 \pm 55) \mathrm{gm}$. Benign enlarged prostate was initial clinical diagnosis in $100 \%$ specimens. Histologically benign enlarged prostate along with inflammation was observed in 168 patients (84\%). The inflammation includes the infarction, necrosis and prostatitis. Carcinoma Prostate was observed in 32 patients $(16 \%)$. Out of these 32 prostate carcinoma specimens, 22 cases were well differentiated, 3 were poorly differentiated and 7 were moderately differentiated after histopathological examination.

Histological studies has shown that prostate carcinoma had higher glandular densities (mean=14.5 acini $/ \mathrm{mm}^{2}$ vs. $6.8 \mathrm{acini} / \mathrm{mm}^{2}$ in benign prostate enlargement) and higher percent stroma (mean $=59 \%$ vs. $49 \%$ ). Mean luminal cell heights in the prostate carcinoma and benign prostate enlargement acini were 11.7 and 19.0 microns, respectively.

The most common complication of prostatectomy was wound infection.

Follow-up records were available for 122 patients, consisting of 119 with benign prostate enlargement and 3 with prostate cancer. There were no persistent obstructive symptoms but some patients still had frequency and urgency, weak erections and backache. Transient urinary incontinence after surgery was reported in 17 patients.

\section{DISCUSSION}

Prostatic disease, mainly benign prostate enlargement and prostate cancer, are among the most common problems in urological practice. Current global statistics series have documented that prostate cancer is the most frequently diagnosed cancer in men and also the most common genito-urinary cancer in men ${ }^{16,17,18}$.

In our current series, the patients assessed over 3 years period accounted for $6 \%$ of surgical admissions. Carcinoma prostate was detected in $16 \%$ of the patients. Another study conducted showed the incidence of cancer arising in patients with $\mathrm{BPH}$ to be approximately $3 \%{ }^{19}$.

The mean age for carcinoma group was 68.3 years as compared to BPH which was 66.1 years. There was no statistically significant age difference between the two groups. This finding was in contrast to a study which showed carcinoma prostate arising a decade later than that of benign prostatic enlargement ${ }^{20}$. Environmental or genetic factors might play a role for this difference ${ }^{21}$. Maximum patients have the symptoms of urinary urgency, hesitancy, frequency and nocturia. As a result they presented as emergencies with acute urinary retention ${ }^{22}$. Hematuria as a presenting symptom was rare in 
patients with benign prostate enlargement and carcinoma of the prostate. Interestingly, most patients who presented with hematuria had prominent median prostatic lobe enlargement at operation. Co-existence of medical conditions like hypertension, diabetes mellitus and chronic obstructive airway diseases were seen in 19 patients.

A DRE and TRUS provide a moderately accurate diagnosis of prostatic carcinoma, shown mostly as hypo-echoic areas within the substance of the gland $^{23}$.

In our study, the most common pathological finding was well differentiated carcinoma (22/32) followed by moderately differentiated carcinoma $(7 / 32)$ and poorly differentiated carcinoma (3/32). This is at variance with separate reports by Catalona et al and George and Sosamma which indicated that poorly differentiated cancer was common accounting for $60 \%$ and $68 \%$ respectively ${ }^{24,25}$.

Any demand for screening patients for prostate cancer is unlikely in the developing world, where resources for health care are more limited. For men 50-69 years old, PSA and DRE screening of carcinoma prostate have shown that overall $\$$ 3574-4627 costs per year. For PSA alone, this figure is $\$ 3872-4965^{26}$.

In our study, the frequency of patients with prostate carcinoma was $16 \%$ among the 200 clinically benign prostate enlargement patients. It reflects an increase incidence of carcinoma due to this condition. Therefore, proper care and early diagnosis may be helpful for early treatment hence decreasing the morbidity and mortality due to this condition. The most common complication after prostatectomy was surgical site infection in our series. Complications after surgery cause increased hospital stay, increase economic burden and utilization of human resources ${ }^{27}$.

In Pakistan, TURP is the commonest procedure, with open prostatectomy reserved only for the occasional very large adenomas that require prolonged time for resection. Even then, such adenomas can still be resected by an experienced endoscopist. In the developing world, the acquisition of endoscopic facilities may be initially expensive but the long term benefits far outweigh their cost.

\section{CONCLUSION}

From this study, it becomes evident that although initially all the parameters can be within the normal range and will carry the diagnosis of benign condition, but upon performing the histopathology it becomes evident that carcinoma does exist. Thus, it is essential that whenever any tissue is taken out of the body, its histopathology must be performed.

\section{REFERENCES}

1. Meares ME. Prostatitis: The med. clinics of North Amer 1991; 75(2):405-424.

2. Dennis LK, Lynch CF, Torner JC. Epidemiologic association between prostatitis and prostate cancer: Urol. 2002;60(1):78-83.

3. Potosky AL, Miller BA, Albersten PC, Kramer BS. The role of increasing detection in the rising incidence of prostate cancer: Jama 1995;273(7):548-552.

4. Center MM, Jemal $A$, et al. International variation in prostate cancer incidence and mortality rates: Euro. urol. 2012;61(6):1079-1092.

5. Brawer MK, Chetner MP, et al. Screening for prostatic carcinoma with prostate specific antigen: The Jour. of urol. 1992;147(3):841-845.

6. Weidner N, Carroll P, Flax J, Blumenfeld W, Folkman J. Tumor angiogenesis correlates with metastasis in invasive prostate carcinoma: The Amer. jour. of path. 1993;143(2): 401.

7. Crawford ED, Schutz MJ, et al. The effect of digital rectal examination on prostate specific antigen levels: Jama 1992;267(16): 2227-2228.

8. Okotie OT, Roehl KA, et al Characteristics of prostate cancer detected by digital rectal examination only: Urol. 2007;70(6):1117-1120.

9. Catalona WJ, Richie JP, et al. Comparison of digital rectal examination and serum prostate specific antigen in the early detection of prostate cancer: results of a multicenter clinical trial of 6,630 men. The Jour. of urol. 1994;151(5):1283-1290.

10. Richie JP, Catalona WJ, et al. Effect of patient age on early detection of prostate cancer with serum prostatespecific antigen and digital rectal examination: Urol. 1993;42(4): 365-374.

11. Amin M, Boccon-Gibod L, Egevad L, Epstein JI, Peter A. (2005). "Prognostic and predictive factors and reporting of prostate carcinoma in prostate needle biopsy specimens: Scand. Jour. of Urol. and Neph. 2005;39(sup216):20-33.

12. Beynon $M$. Patients requiring surgery on the male reproductive system: Nursing the Surgical Patient $2005 ; 349$.

13. Stimoson JB, Finn SD. Benign prostatic hyperplasia and its treatment: Jour. of Gen. Int. Med. 1990;5(2):153165.

14. Barry MJ, Fowler FJ. The American Urological Association symptom index for benign prostatic hyperplasia: The Jour. of urol. 1992;148(5 Part 1):15491557. 
15. Epstein JI, Allsbrook Jr WC, Amin MB, Egevad LL. The 2005 International Society of Urological Pathology (ISUP) consensus conference on Gleason grading of prostatic carcinoma: The Amer. jour. of surg. path. 2005;29(9):1228-1242.

16. Eble JN, Sauter G, Epstein JI, Sesterhenn IA. Pathology and genetics of tumors of the urinary tract and male genital organs. Lyon: IARC Press;2004.159214.

17. Talukder SI, Roy MK, Azam MS, Haq MH, Hague MA, Saleh AF. Histopathological patterns of prostate specimens in Mymensing. Dinajpur Med Coll J 2008;1:29-32.

18. Mandong BM, lya D, Obekpa PO, Orkar KS. Urological tumors in Jos university teaching hospital, Jos, Nigeria (A hospital based histopathological study). Niger J Surg Res 2000;2:108-13.

19. Karim $\mathrm{H}$, Hooda $\mathrm{M}$, Islam $\mathrm{M}$, et al. Incidence of chips positive carcinoma of prostate following TURP for clinically benign prostatic hyperplasia patients with normal serum PSA. Bangladesh J Urol. 2011;14(1):1418.

20. Levine RL, Wilchinsky M. Adenocarcinoma of the prostate: a comparison of the disease in blacks versus whites. The Jour. of urol. 1979;121(6):761-762.

21. Yu E, Siegal J, et al. Histologic differences in benign prostate hyperplasia between Chinese and American men: The Prostate 1997;31(3):175-179.

22. Walsh PC. Surgery and the reduction of mortality from prostate cancer. N Engl J Med.2002;347:839-840.

23. Waterhouse RL, Resnick MI. The use of transrectal prostatic ultrasonography in the evaluation of patients with prostatic carcinoma: The Jour. of urol. 1989;141(2):233-239.
24. Catalona WJ, Anterior JA, Roehi KA, Moul JW. Screening of prostate cancer in high risk population. $J$ Urol 2002;168:1980-3.

25. George E, Sosamma T. A histopathologic survey of prostatic disease in the Sultanate of Oman. Internet $J$ Pathol 2003;2:2.

26. Benoit RM, Gronberg H, Naslund MJ. A quantitative analysis of the costs and benefits of prostate cancer screening. Prostate Cancer Prostatic Dis. 2001;4(3):138-45.

27. Hradec EA. Bladder substitution: indications and results in 114 operations. The Jour. of urol. 1965;94(4):406-417.

28. Aslam M, Shahid N. Ahmad Sheikh N, Saleem S. Spectrum of prostatic lesions: Int. Arch. Med. 2013;6:36.

29. Thomas DJ, Balaji VJ, Coptcoat MJ, Abercromble GF. Acute urinary retention secondary to carcinoma of the prostate: J. R. Soc. Med. 1992;85(6):318-319.

30. Abedi AR, Fallah-karkan M, Allameh F, Ranjbar A, Shadmehr A. Incidental prostate cancer: a 10 year review of a tertiary centre, Tehran, Iran: Res. Rep. Urol. 2018;10:1-6.

31. Gunda D, Kido, et al. Prevalence and associated factors of incidentally diagnosed prostatic carcinoma among patients who had TURP: Ethiop. J. Health Sci. 2018;28(1):11-18.

32. Krupski TL, Stukenborg GJ, Moon K, Theodorescu D. The relationship of palliative trans urethral resection of the prostate with disease progression in patients with prostate cancer: BJU Int. 2010;106(10)1477-1483. 